\title{
Senate Republican Leadership Releases Revised ACA Repeal and Replace Bill
}

Today, the Senate Republican leadership released a revised version of a bill to repeal and replace the Affordable Care Act (ACA). The new bill draft includes an amendment sponsored by Sen. Cruz (R-TX) that permits insurers to offer health insurance plans on the ACA exchanges that do not cover the ACA's 10 essential health benefits $(\mathrm{EHB})$ as long as they offer at least one other plan that provides full coverage of EHB's. The bill also includes more funding for opioid addiction and for state initiatives to reduce insurance premiums and additionally, some flexibility for state Medicaid funding in the event of a public health crisis. The bill must still receive a cost estimate from the Congressional Budget Office (CBO), which will include the impact of the bill on insurance coverage levels, expected out Monday. The ATS remains deeply concerned about the bill because under the Cruz proposal, insurance coverage costs for people with pre-existing conditions would soar, leaving coverage unaffordable for many people with chronic respiratory conditions. The Senate leadership aims to begin voting on the bill by the middle of next week in an open amendment process, so changes could be made to the bill with subsequent votes occurring quickly.

Just before the revised leadership bill was introduced, Sen. Graham (R-SC) and Cassidy (R-LA) released their own ACA repeal and replace bill, which focuses on sending ACA funding directly to the states, rather than the federal government and would preserve more state Medicaid funding. The Graham/Cassidy proposal would also permit states to waive the ACA's EHB's although full details of this bill are not yet clear and some aspects are still under revision.

Despite the release of the Senate leadership's new bill, it is still not at all clear whether it will gain the support of all Senate Republicans, a number of whom have concerns with the funding reductions to Medicaid.

Nuala S. Moore

American Thoracic Society

Washington, DC USA 